\title{
Characterization of microstructure, toughness, and chemical composition of friction-welded joints of UNS S32205 duplex stainless steel
}

\author{
Puthuparambil Madhavan AJITH ${ }^{1}$, Paulraj SATHIYA ${ }^{1, *}$, Sivanandam ARAVINDAN ${ }^{2}$ \\ ${ }^{1}$ Department of Production Engineering, National Institute of Technology Tiruchirappalli-620015, Tamilnadu, India \\ ${ }^{2}$ Department of Mechanical Engineering, Indian Institute of Technology Delhi New Delhi-110016, India \\ Received: 13 December 2013 / Revised: 23 January 2014 / Accepted: 14 February 2014 \\ C The author(s) 2014. This article is published with open access at Springerlink.com
}

\begin{abstract}
Friction welding is a solid-state joining process which is applied extensively because of its advantages such as low heat input, efficient application, ease in manufacturing, and environmental friendliness. The present study investigates the mechanical and metallurgical properties of UNS S32205 duplex stainless steel frictionwelded joints. The process parameters, namely friction pressure, upsetting pressure, and rotational speed are individually varied from low level to high level (within the range of the machine setup) and their effects on the joint properties are analyzed. The partial-deformation zone had higher hardness than the weld and base metal. The toughness of the joints was evaluated at room temperature and at subzero temperature conditions. The impact toughness of the friction-welded joints was found to be superior to fusion-joined duplex stainless steel in room and cryogenic conditions.
\end{abstract}

Keywords: friction welding; duplex stainless steel; hardness; toughness; microstructure

\section{Introduction}

Duplex stainless steel (DSS) has a two-phase structure of ferrite and austenite, and gets the beneficial effects of both phases: high strength (from the ferrite) and toughness (from the austenite) even at low temperatures. Furthermore, the material offers good resistance to localized corrosion because of high $\mathrm{Cr}, \mathrm{Mo}$, and $\mathrm{N}$ additions, and to cracks caused by stress corrosion because of the ferrite content [1]. Comprehensive analyses of the effects of $\mathrm{N}$ on the fatigue behavior of the dual phases of stainless steels were performed. Addition of $\mathrm{N}$ in DSS tended to produce more austenite phase than ferrite phase, which appeared most beneficial for controlling the softening and satisfactory fatigue properties [2,3]. The phase balance in DSS, obtained by careful heat treatment, was

* Corresponding author: Paulraj SATHIYA.

E-mail: psathiya@nitt.edu crucial for the mechanical properties. DSS solidified as ferrite, and on further cooling it transformed partially to austenite. During cooling, austenite was first precipitated at the grain boundaries, then by Widmanstätten plates, and finally as intragranular precipitates. A small grain size enhanced the austenite reformation because of increased grain boundary area $[4,5]$. DSS had good weldability by conventional arc-welding methods as long as the heat input and interpass temperatures were limited to ensure a proper $\gamma$-to- $\delta$ ratio in the weld metal and heat-affected zone (HAZ) [6]. Apart from the microstructural features, cold deformation was found to improve the yield strength, tensile strength, and hardness of DSS, while it slightly reduced the elongation [7]. The volume fraction of $\sigma$ phase continuously increased with increasing aging time and the precipitation of Moenriched $\chi$ phase [8]. Several unwanted secondary phases may form in DSS and weld metals subjected to temperatures in the range of $300{ }^{\circ} \mathrm{C}$ to $1,100{ }^{\circ} \mathrm{C}$ by 
heat treatment or welding operations [9]. The $\chi$ phase usually existed in much smaller quantities than the $\sigma$ phase [6] and was associated with a reduction in both impact properties and corrosion resistance of the welds [10]. The ferritic solidification promoted resistance to solidification cracking in the welds [11]. Higher ferrite content and coarse grains were the other factors that decreased both the corrosion resistance and the mechanical properties of welded joints [12] during the solidification in welds of a DSS with $(\mathrm{Cr} / \mathrm{Ni})_{\mathrm{eq}}=1.8$ at various cooling rates [13]. The interfacial characteristics and dynamic processes of $\mathrm{Au}$ - and $\mathrm{Cu}$-wire bonding and overhang bonding in the microelectronics packaging industry were studied. It was concluded that a thick-Al approach led to improved reliability of $\mathrm{Cu}$-wire bonding. By decreasing the hardness of the overhang die, which significantly reduced the impact of the overhang bonding process, and improving features of the hard Cu-wire overhang bonding, $\mathrm{Cu}$-wire overhang bonding performance significantly increased [14]. The intermetallic phases $\mathrm{Al}_{2} \mathrm{Au}, \mathrm{AlAu}_{4}$, or $\mathrm{Al}_{3} \mathrm{Au}_{8}$ were formed at the $\mathrm{Au}-\mathrm{Al}$ bond interface, and the thickness of the intermetallic phases was $100-300 \mathrm{~nm}$. The microstructural characteristics of $\mathrm{Au} / \mathrm{Al}$ bonded interfaces were examined [15-17]. Atomic diffusion took place at the bond interface to enhance the microstructural strength aspects, which increased beyond that of the base materials. The fracture surfaces of bonded interfaces were characterized by dimpled rupture. The tensile fractures occurred in the base metal and not in the bond interface because of the presence of an intermetallic compound in the joint interface. Theoretical and experimental analyses of atom diffusion characteristics were performed on wire-bonding interfaces, on a die with Al-pad in the $\mathrm{T} / \mathrm{S}-2100$ ultrasonic wire bonder. Within several tens of milliseconds, the thickness of atom diffusion in the ultrasonic bonding interface was approximately 100-300 $\mathrm{nm}$ for the given bonding parameters, which formed good bonding strength [18].

Welding of UNS S32205 DSS joints by the frictionwelding process and the effect of individual process parameters, namely friction pressure (FP), upsetting pressure (UP), and speed of rotations (SR), on the mechanical and metallurgical properties, have not been discussed in detail in any previous work. A detailed experiment of UNS S32205 DSS joints by friction welding was performed to investigate the effect of the individual parameters on the mechanical and metallurgical properties and corrosion resistance of the DSS weld.

\section{Experimental methods}

Rods of DSS (UNS S32205) of $15 \mathrm{~mm}$ diameter and $100 \mathrm{~mm}$ length were joined using the friction-welding process. The chemical composition of the base material was: $\mathrm{C}=0.021, \mathrm{Si}=0.357, \mathrm{Mn}=1.61, \mathrm{~S}=0.001, \mathrm{P}=0.026$, $\mathrm{Cr}=22.50, \mathrm{Mo}=3.38, \mathrm{Ni}=4.79, \mathrm{~N}=0.193$, and the rest Fe. The microstructure of the base material (in annealed condition) (Fig. 1) showed distribution of the austenite and ferrite phases. The average grain size was 21.7 microns.

Before welding, each faying surface was swiped with acetone to ensure cleanliness of the surfaces. The friction-welding parameters, namely FP (45-125 $\mathrm{MPa})$, UP (140-200 MPa), and SR (1,000-2,000 rpm) were chosen based on the machine capacity, i.e., low, medium and high levels. In each set of welding trials, one parameter was varied from low level to high level, while the rest of the parameters were kept as constant. The experimental friction-welding parameter values (burn-off length kept as constant $(2 \mathrm{~mm})$ for all 15 experiments) are presented in Table 1 . Four joints were prepared and their average values are presented.

A continuous-drive friction-welding machine with a maximum load of $150 \mathrm{kN}$ was used for welding. The specimens were mounted and later flattened and then polished using $\mathrm{SiC}$ abrasive paper with grit ranges from 180 to 1,200 . Then, the samples were lightly polished using $3 \mu \mathrm{m}$ diamond paste. Samples

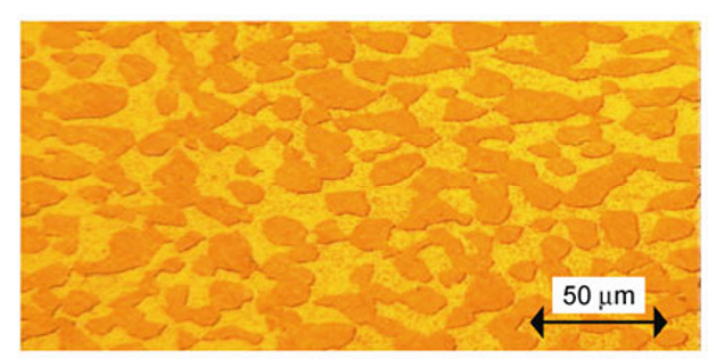

Fig. 1 DSS microstructure in the annealed condition. 
Table 1 List of friction-welding parameters and their values used in the preparation of weldment.

\begin{tabular}{cccccccccccccccc}
\hline Exp. No. & 1 & 2 & 3 & 4 & 5 & 6 & 7 & 8 & 9 & 10 & 11 & 12 & 13 & 14 & 15 \\
\hline FP (MPa) & 45 & 65 & 85 & 105 & 125 & 45 & 45 & 45 & 45 & 45 & 45 & 45 & 45 & 45 & 45 \\
UP (MPa) & 140 & 140 & 140 & 140 & 140 & 140 & 155 & 170 & 185 & 200 & 140 & 140 & 140 & 140 & 140 \\
SR (rpm) & 1,000 & 1,000 & 1,000 & 1,000 & 1,000 & 1,000 & 1,000 & 1,000 & 1,000 & 1,000 & 1,000 & 1,250 & 1,500 & 1,750 & 2,000 \\
\hline
\end{tabular}

were then washed, cleaned by acetone, and dried. This was followed by electrolytic etching in $10 \%$ oxalic acid at $9 \mathrm{~V}$ for $30 \mathrm{~s}$, in accordance with ASTM E3-11. Chemical composition of the weld metal was determined by spectra chemical analysis. Ferrite number (FN) was measured using feritscope M30 and the percentage of ferrite was calculated using $\mathrm{Cr}_{\text {eq }}$ and $\mathrm{Ni}_{\text {eq. }}$. The weld specimens were prepared for Charpy test in accordance with the ASTM E-23 standard. Impact toughness of the joints was determined by a pendulum impact testing machine at different temperatures such as room temperature $\left(30^{\circ} \mathrm{C}\right)$ and cryogenic temperatures $\left(-50{ }^{\circ} \mathrm{C},-100{ }^{\circ} \mathrm{C},-150{ }^{\circ} \mathrm{C}\right.$, and $\left.-196{ }^{\circ} \mathrm{C}\right)$, respectively. A microhardness survey was performed using a HMV-2000 Vickers microhardness tester at $500 \mathrm{~g}$ load for $10 \mathrm{~s}$. The microhardness tests were performed on a transverse section of the weld center to identify the possible effects of microstructural heterogeneities in the weld. Samples for characterization were prepared using standard metallographic techniques. The weld-metal grain size was measured in accordance with ASTM standards. The fractured surfaces were examined through a JEOL JSM-5610 LV scanning electron microscope (SEM) equipped with an energy-dispersive spectrometer (EDS) to perform a quantitative analysis of the welds.

\section{Results and discussions}

\subsection{Macrograph of the welded joints}

The typical cross-sectional views of the friction-welded samples are presented in Fig. 2 and they revealed no defects in the joint zone.

From Fig. 2, it can be inferred that all the frictionwelded samples processed at different parameters exhibited symmetrically shaped flash. This showed that there was equal softening of metal on both sides of the joint.

\subsection{Influence of chemical composition on phase fractions (austenite and ferrite) of the weld}

In general, the volume of ferrite fraction content was much higher than that of the austenite content in the weld and this could result in the loss of lowtemperature notch toughness and corrosion resistance in the weld [19]. Careful control over weld metal composition and weld temperature was exercised during welding to overcome the above mentioned issues. From the weld micrographs, the percentages of ferrite and austenite phases were mapped (Fig. 3) using image-analyzing software, and the ferrite number was measured using a Fischer Feritscope MP 30. Their average values were 53.58 for weld metal, 45.15 for PDZ, 47.58 for base metal, and 46.33 for the average predicted ferrite number.

It was found that the percentage of ferrite phase was higher than the austenite phase for all the weld metal; however, it was lower in the partially deformed zone (PDZ). The ferrite percentage of the weld was predicted by modified Schaffler diagram and the chemical composition of the weld metals was analyzed by EDS analysis. A typical EDS spectrum for PDZ and weld metal is shown in Figs. 4(a) and 4(b), respectively. The $\mathrm{Cr}_{\mathrm{eq}} / \mathrm{Ni}_{\mathrm{eq}}$ ratio was calculated from the following

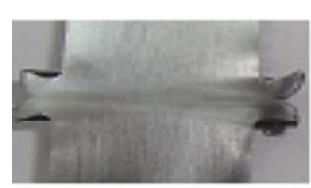

(a) Exp. No. 1

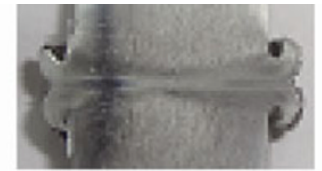

(b) Exp. No. 2

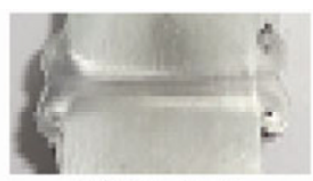

(c) Exp. No. 3

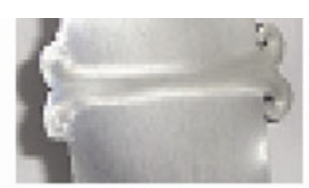

(d) Exp. No. 4

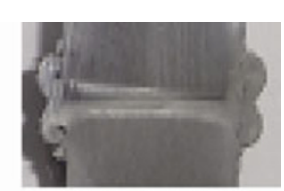

(e) Exp. No. 5

Fig. 2 Typical cross-sectional views of the friction-welded sample. 


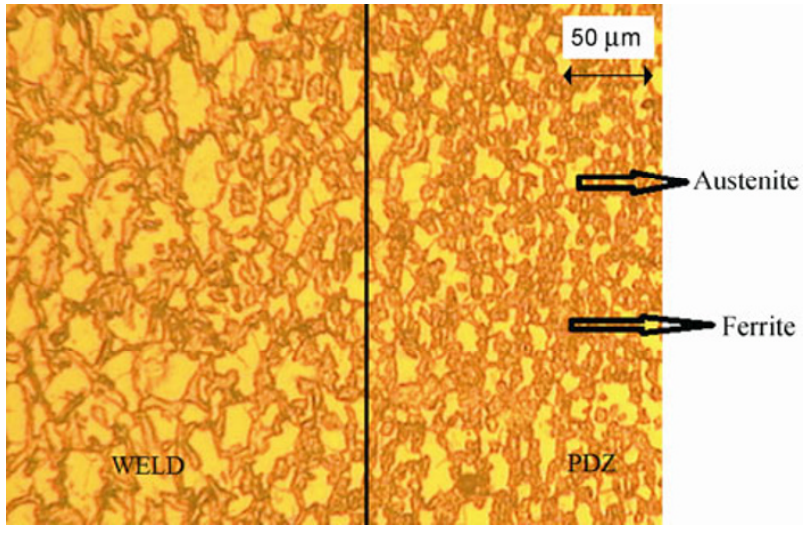

Fig. 3 Typical weld metal microstructure of DSS.

equations and the value was 1.71-1.88 for weld metal.

$$
\begin{gathered}
\mathrm{Cr}_{\text {eq }}=\% \mathrm{Cr}+1.5 \% \mathrm{Si}+1.4 \% \mathrm{Mo}+\% \mathrm{Nb}-4.99 \\
\mathrm{Ni}_{\text {eq }}=\% \mathrm{Ni}+30 \% \mathrm{C}+0.5 \% \mathrm{Mn}+26(\% \mathrm{~N}-0.02)+2.77
\end{gathered}
$$

The values of $\mathrm{Cr}_{\mathrm{eq}}$ and $\mathrm{Ni}_{\mathrm{eq}}$ and the average values of $\mathrm{Cr}_{\text {eq }}$ and $\mathrm{Ni}_{\text {eq }}$ were calculated; the values for the weld metal were: $\mathrm{Cr}_{\mathrm{eq}}=22.82, \mathrm{Ni}_{\mathrm{e}}=12.81$, and $\mathrm{Cr}_{\mathrm{eq}} / \mathrm{Ni}_{\mathrm{eq}}=1.78$, and for the base metal, $\mathrm{Cr}_{\text {eq }}=22.69, \mathrm{Ni}_{\text {eq }}=13.59$, and $\mathrm{Cr}_{\mathrm{eq}} / \mathrm{Ni}_{\mathrm{eq}}=1.66$.

A modified Schaffler diagram (Fig. 7) indicates the relation between $\mathrm{Cr}$ and $\mathrm{Ni}$ equivalents and the phases present in the microstructure [20].

It was reported by Suutala [21] that when the ratio of $\mathrm{Cr}_{\mathrm{eq}} / \mathrm{Ni}_{\mathrm{eq}}$ was lower than 1.35 , solidification resulted in austenitic formation and when it was greater than 1.35, ferrite was formed. It was clearly understood that the $\mathrm{Cr}_{\mathrm{eq}} / \mathrm{Ni}_{\mathrm{eq}}$ ratio was between 1.71 and 1.88 for all the weld metal. The ferrite percentage test clearly indicated that the percentage of ferrite was greater in the weld zone compared to the PDZ. Matrix of the weld contained ferrite and austenite, and the austenite islands in the PDZ had more grain boundaries than the base metal. The elongation of grains took place in the rotating direction of the weld.

\subsection{Microstructure of the PDZ and weld metal}

The PDZ and weld metal microstructure are presented in Fig. 5.

Figure 5 clearly distinguishes between the PDZ and the weld metal. It was observed that no internal defects were found in any of the PDZ or weld metal microstructures. This confirmed the good metallurgical joint of the weld. The PDZ had finer grains than the weld metal. The weld metal microstructure consisted of approximately equal volumes of both ferrite and austenite phases. The weld metal microstructure consisted of large ferrite grains compared with the PDZ microstructure and its continuous networks of austenite at the ferrite grain boundaries. Figure 5 reveals no intragranular austenite precipitates. PDZ microstructure has finer grain size than that of the weld microstructure. In Fig. 5(e), the grains are elongated toward the weld center line in the external rotating direction. This was caused by the high amount of friction and upsetting pressure. Low friction pressure resulted in coarse grains, as observed in Fig. 5(b). The weld metals were further investigated by means of $X$-ray diffraction for phase identification, as presented in Fig. 6.

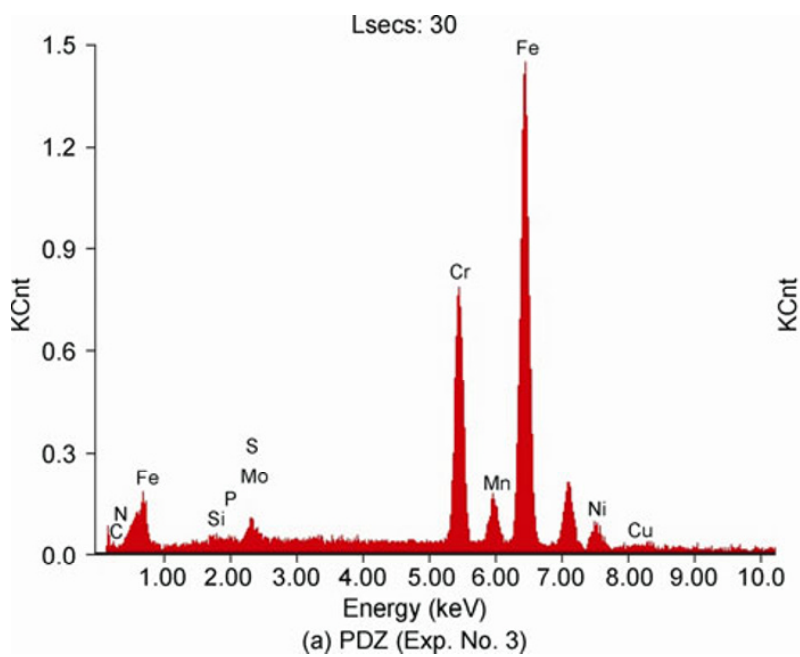

(a) PDZ (Exp. No. 3)

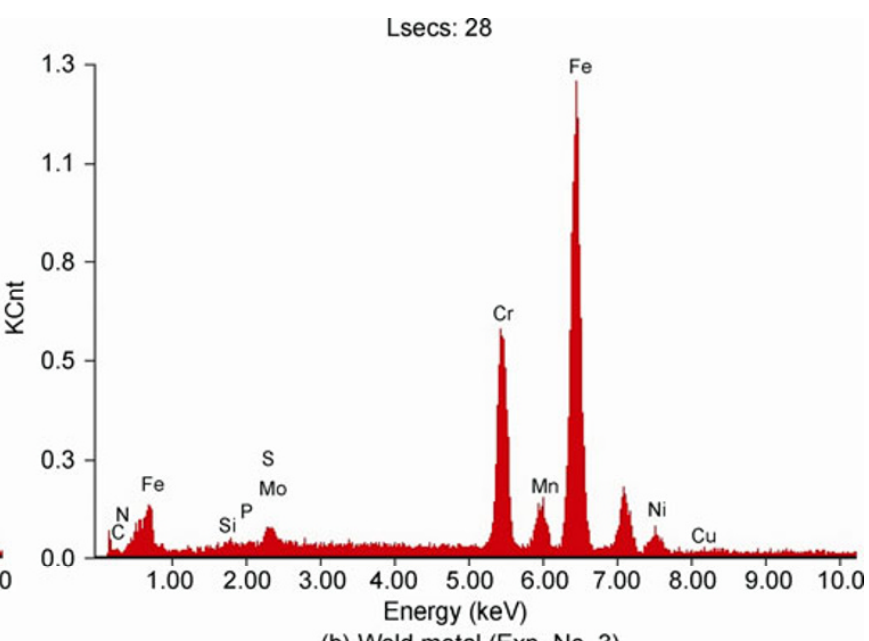

(b) Weld metal (Exp. No. 3)

Fig. 4 Typical EDS spectrum for PDZ and weld metal. 


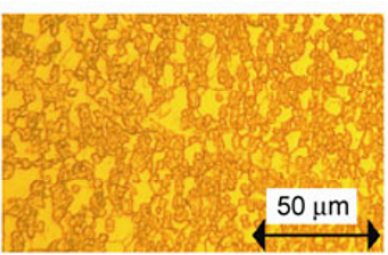

(a) Exp. No. 1 PDZ

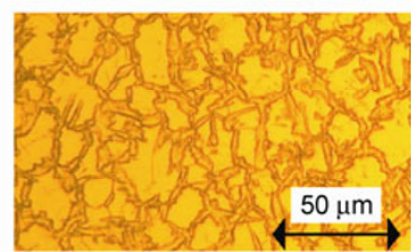

(b) Exp. No. $1 \mathrm{WM}$

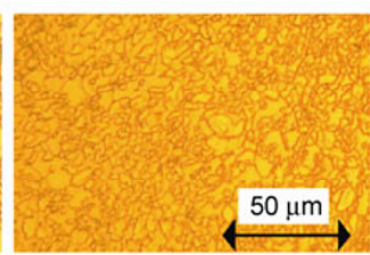

(c) Exp. No. 2 PDZ

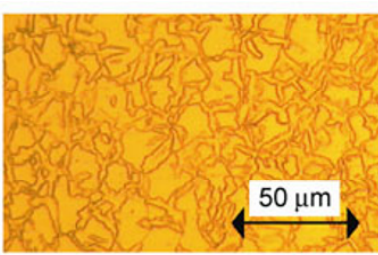

(d) Exp. No. 2 WM

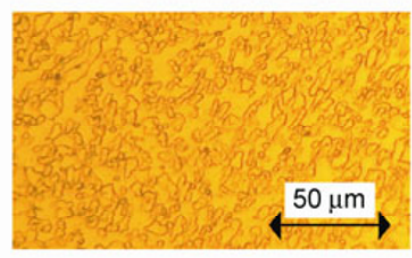

(e) Exp. No. 15 PDZ

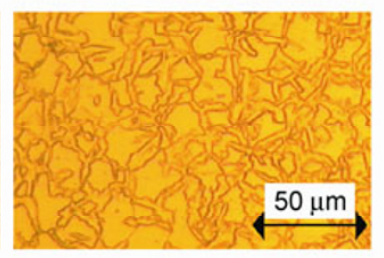

(f) Exp. No. 15 WM

Fig. 5 Typical microstructure of PDZ and weld metal (WM).

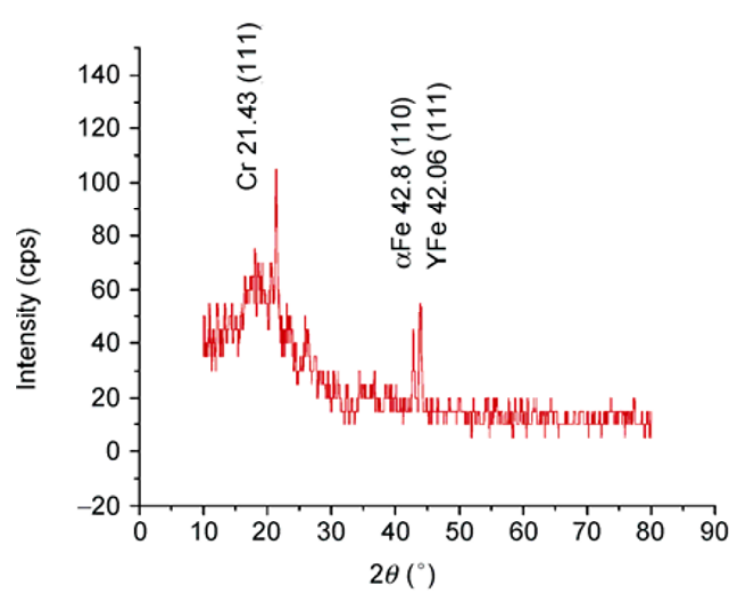

(a) Exp. No. 3

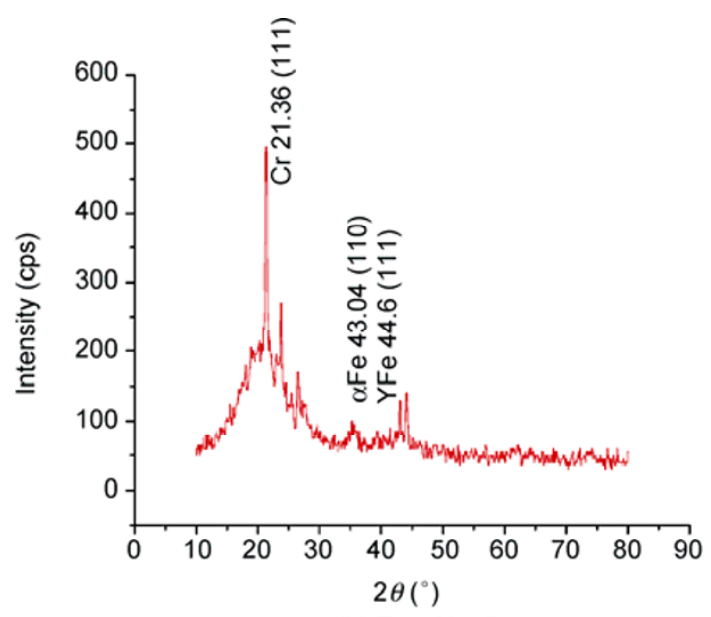

(b) Exp. No. 5

Fig. 6 X-ray diffraction patterns of friction welds.

The main peaks in all these patterns correspond to the austenite $(\gamma)$ and ferrite $(\alpha)$ phases. Thus, no other carbides of intermetallic were revealed by X-ray diffraction patterns.

\subsection{Microhardness of the weld}

The microhardness (VHN) test was performed on the etched transverse cross-section of the weld zone at a load of $0.5 \mathrm{~kg}$, which was applied for duration of $10 \mathrm{~s}$. The hardness values were measured $1 \mathrm{~mm}$ below the upper surface and $1 \mathrm{~mm}$ above the lower surface. Five measurements in each weld zone were taken at regular intervals and the average measured hardness and grain size values are presented in Table 2 .
Table 2 Hardness and grain size values.

\begin{tabular}{cccccc}
\hline & \multicolumn{3}{c}{ Hardness value (Hv) } & \multicolumn{2}{c}{ Grain size (microns) } \\
\cline { 2 - 6 } Exp. No & $\begin{array}{c}\text { Weld } \\
\text { metal }\end{array}$ & $\begin{array}{c}\text { Partially } \\
\text { deformed } \\
\text { zone }\end{array}$ & $\begin{array}{c}\text { Base } \\
\text { metal }\end{array}$ & $\begin{array}{c}\text { Weld } \\
\text { metal }\end{array}$ & $\begin{array}{c}\text { Partially } \\
\text { deformed } \\
\text { zone }\end{array}$ \\
\hline Average & 290.01 & 305.37 & 266.14 & 21.87 & 10.37 \\
\hline
\end{tabular}

From Table 2, it is clear that hardness in the PDZ was greater than in the weld metal. This is attributed to the finer grain size of the PDZ than the weld and base metal. Hardness in the weld zone was higher than in the base metal because of the increased ferrite percentage. The strength was enhanced by increasing the volume fraction of ferrite. The weld zone had fine 
equiaxed grains with a distorted structure caused by mechanical deformation of the material and the heat effect (Fig. 3). Fine equiaxed grains were more pronounced in the austenite phase. This shows that the ferrite had a higher diffusion rate than austenite, producing a recrystallization followed by grain growth. In addition, there was no formation of deleterious phases like sigma, for example, commonly found in the weldments obtained by other processes. The absence of these phases was a result of the faster cooling of the weld zone and faster nucleation and growth compared with the fusion process. During friction welding, cooling was often faster and there was less time for austenite to form. Hence, all samples contained comparatively more ferrite in the weld zone than in the base metal.

\subsection{Charpy V-notch impact toughness of welds}

To evaluate the impact toughness values of the welded joint, a series of Charpy V-notch tests were performed on friction-welded joints at various temperatures, such as room temperature $\left(\mathrm{RT}=30^{\circ} \mathrm{C}\right)$ and cryogenic temperatures $\left(-50{ }^{\circ} \mathrm{C},-100{ }^{\circ} \mathrm{C},-150{ }^{\circ} \mathrm{C}\right.$, and $\left.-196^{\circ} \mathrm{C}\right)$; the tested values are presented in Table 3 .

The impact toughness of base metal was $160 \mathrm{~J}$, which was lower than the weld metal impact strength. From Table 3, it is clear that higher impact toughness values were obtained for all the tested temperatures. The impact energy of DSS by TIG and SMAW processes with different low temperatures was found, for the SMAW process, to be $-50{ }^{\circ} \mathrm{C}=15 \mathrm{~J},-100{ }^{\circ} \mathrm{C}=7 \mathrm{~J}$, $-150{ }^{\circ} \mathrm{C}=6 \mathrm{~J}$, and $-196{ }^{\circ} \mathrm{C}=5 \mathrm{~J}$; and for the TIG process, $-50{ }^{\circ} \mathrm{C}=11 \mathrm{~J},-100{ }^{\circ} \mathrm{C}=9 \mathrm{~J},-150{ }^{\circ} \mathrm{C}=6 \mathrm{~J}$, and $-196{ }^{\circ} \mathrm{C}=4 \mathrm{~J}$ [22]. The friction-welded impact energy was much higher than the arc welded DSS joints. From Table 3, the impact toughness values were observed to be reduced with the reduction in temperature from room temperature to cryogenic temperatures. The enhancement in impact strength (toughness) was approximately $13.5 \%$ (RT), 13.54\% $\left(-50{ }^{\circ} \mathrm{C}\right), 43.5 \%\left(-100{ }^{\circ} \mathrm{C}\right), 39.5 \%\left(-150{ }^{\circ} \mathrm{C}\right)$, and $23.2 \%$ $\left(-196^{\circ} \mathrm{C}\right)$ when compared with the base metal. The ferrite content (average $=51.8$ ) was almost the same for all the impact samples after testing at $-196{ }^{\circ} \mathrm{C}$. This could be attributed to the negligible amount of plastic deformation exerted at $-196{ }^{\circ} \mathrm{C}$ and accordingly, no transformation of austenite to deformation-induced martensite would take place. It could be observed that the deformation mechanism of DSS consisted of many factors, including the generation of stacking faults, strain-included martensite transformation, and ferrite phase deformation. At $-196{ }^{\circ} \mathrm{C}$, the friction welds were metastable and underwent a partial transformation to martensite during deformation. Evidence of martensitic transformation had been detected in the crack-tip plastic zone of austenitic and DSS impact specimens at cryogenic temperatures as low as liquid nitrogen [23]. At cryogenic temperatures, welds typically exhibited higher strength and lower toughness than their base metal. The inferior weld metal toughness was associated with high nonmetallic inclusion and delta ferrite content and higher strength level [24]. The ferrite was of a body-centered cubic (BCC) structure, and its yield strength was a function of temperature, i.e., it increased as the temperature was lowered because of increased lattice friction stress and the pinning of mobile dislocations with interstitial atoms ( $\mathrm{C}$ and $\mathrm{N})$. On the other hand, the cleavage fracture stress of ferrite was not a function of temperature and was only varied by microstructural parameters such as grain size and dislocation density [25]. The relation between the individual parameters with respect to the toughness of the weld is plotted in Fig. 7.

Table 3 Impact toughness of friction welds.

\begin{tabular}{cccccccccccccccccc}
\hline Exp. No & 1 & 2 & 3 & 4 & 5 & 6 & 7 & 8 & 9 & 10 & 11 & 12 & 13 & 14 & 15 \\
\hline & $\mathrm{RT}\left(30^{\circ} \mathrm{C}\right)$ & 182 & 195 & 201 & 206 & 208 & 163 & 166 & 178 & 182 & 185 & 165 & 168 & 170 & 174 & 182 \\
& $-50^{\circ} \mathrm{C}$ & 80 & 85 & 90 & 92 & 95 & 62 & 65 & 68 & 72 & 76 & 75 & 78 & 80 & 85 & 89 \\
Impact & $-100^{\circ} \mathrm{C}$ & 60 & 62 & 62 & 55 & 60 & 60 & 59 & 54 & 58 & 51 & 58 & 60 & 50 & 53 & 59 \\
strength (J) & $-150^{\circ} \mathrm{C}$ & 43 & 42 & 45 & 47 & 41 & 42 & 42 & 46 & 44 & 41 & 42 & 40 & 38 & 35 & 40 \\
& $-196^{\circ} \mathrm{C}$ & 30 & 25 & 21 & 19 & 18 & 23 & 20 & 18 & 16 & 14 & 24 & 18 & 14 & 13 & 15 \\
\hline
\end{tabular}



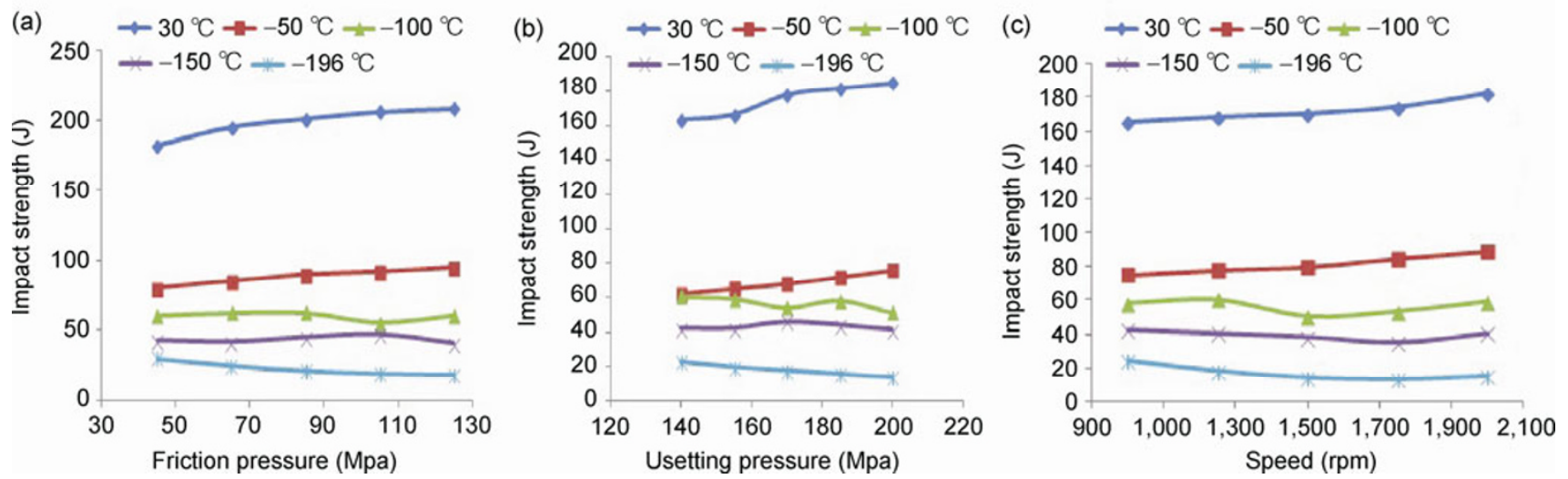

Fig. 7 Effect of friction-welding process parameters on impact strength.

From Fig. 7, it is clear that impact strength of the weld decreased as temperature decreased. Figure 7(a) indicates the variation of impact strength with the increase in friction pressure. The value of impact strength is observed to be increased with the increase in friction pressure for the room temperature and $-50{ }^{\circ} \mathrm{C}$ testing conditions. The trend is observed to be changing with further lower temperatures. Similar trend is seen in impact strength with the variation of upsetting pressure (Fig. 7(b) and rotational speed (Fig. 7(c)). The fractured surfaces of the impact specimens were analyzed using SEM. Fractrographs of the fractured surfaces for various temperatures are shown in Fig. 8 at room temperature, Fig. 9 at $-50{ }^{\circ} \mathrm{C}$, Fig. 10 at $-100{ }^{\circ} \mathrm{C}$, Fig. 11 at $-150{ }^{\circ} \mathrm{C}$, and Fig. 12 at $-196^{\circ} \mathrm{C}$.

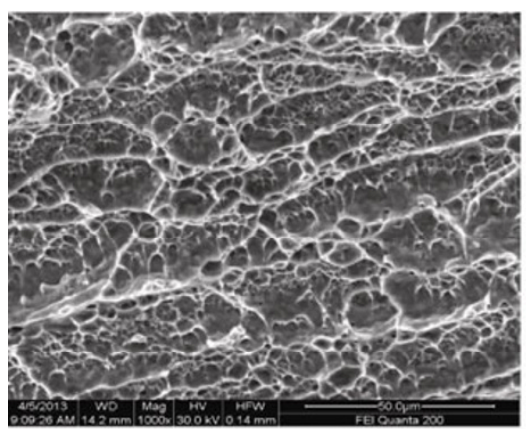

(a) Exp. No. 1

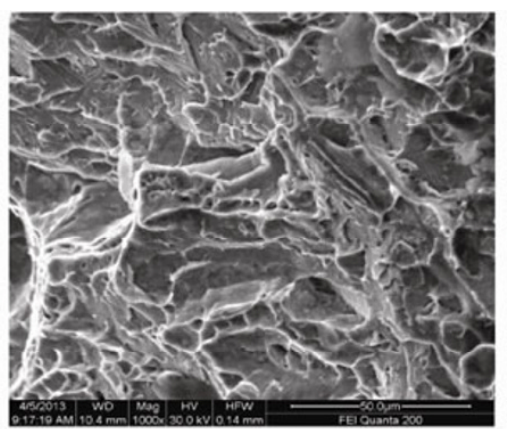

(b) Exp. No. 7

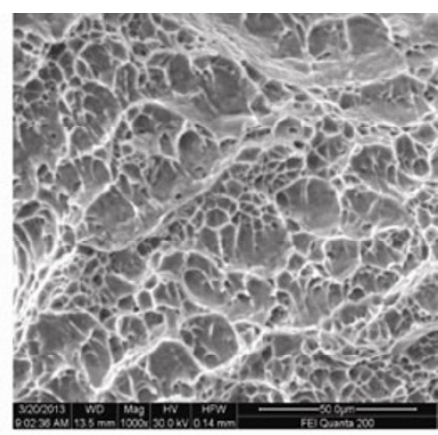

(c) Exp. No. 13

Fig. 8 Fractrographs of the Charpy V-notch tested samples at room temperature.

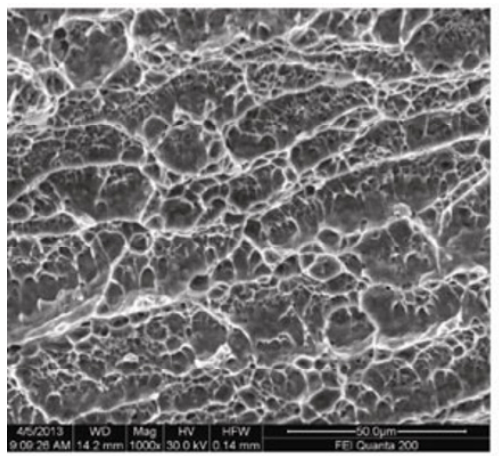

(a) Exp. No. 3

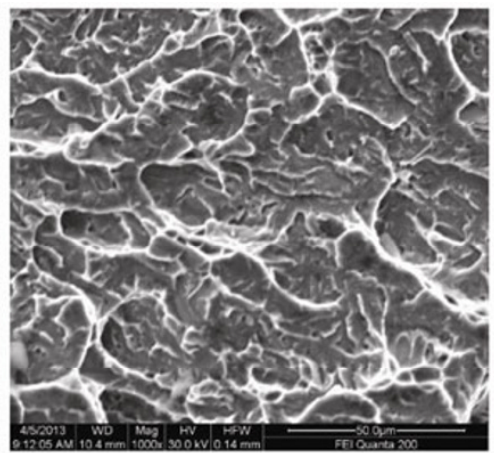

(b) Exp. No. 7

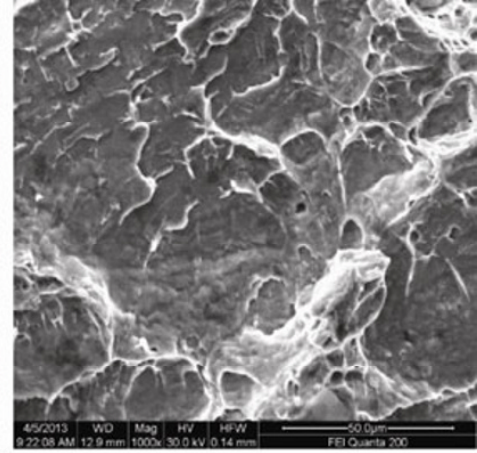

(c) Exp. No. 13

Fig. 9 Fractrographs of the Charpy V-notch tested samples at $-50{ }^{\circ} \mathrm{C}$. 


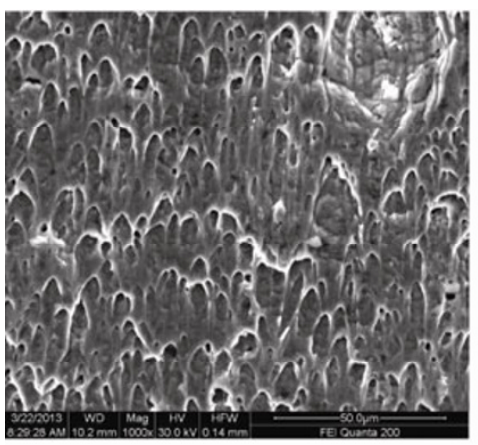

(a) Exp. No. 4

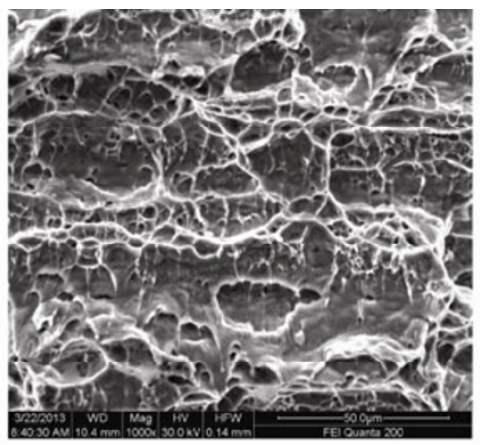

(b) Exp. No. 8

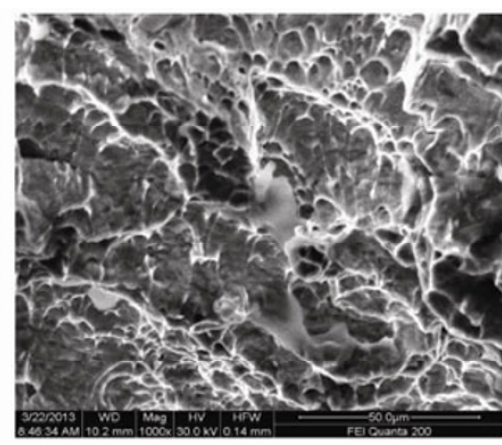

(c) Exp. No. 12

Fig. 10 Fractrographs of the Charpy V-notch tested samples at $-100{ }^{\circ} \mathrm{C}$.

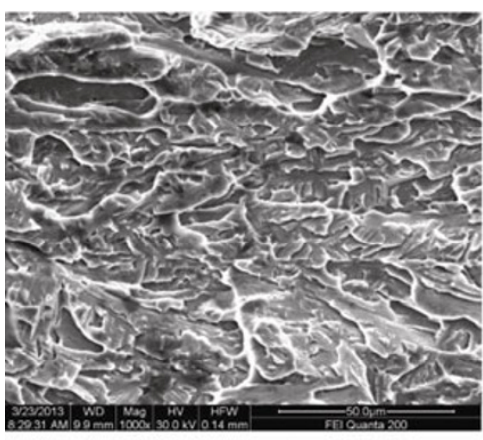

(a) Exp. No. 5

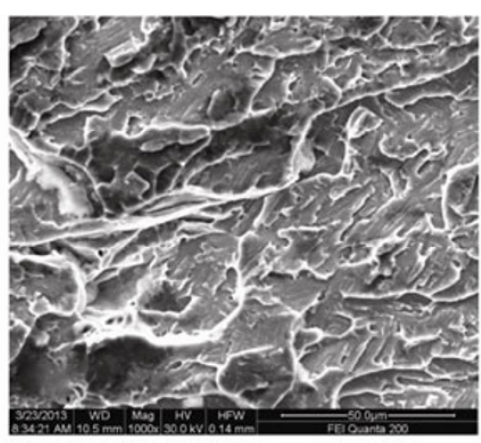

(b) Exp. No. 10

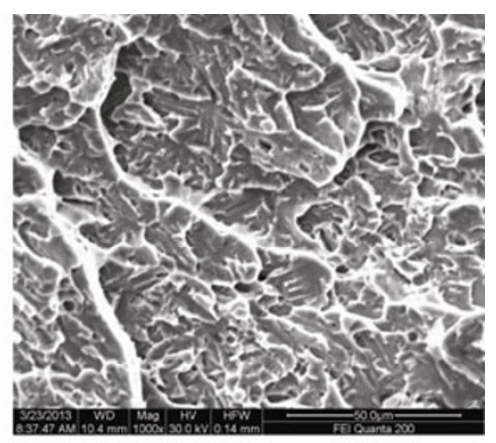

(c) Exp. No. 14

Fig. 11 Fractrographs of the Charpy V-notch tested samples at $-150{ }^{\circ} \mathrm{C}$.

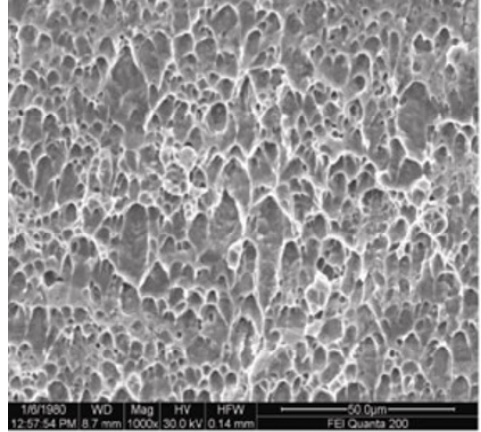

(a) Exp. No. 4

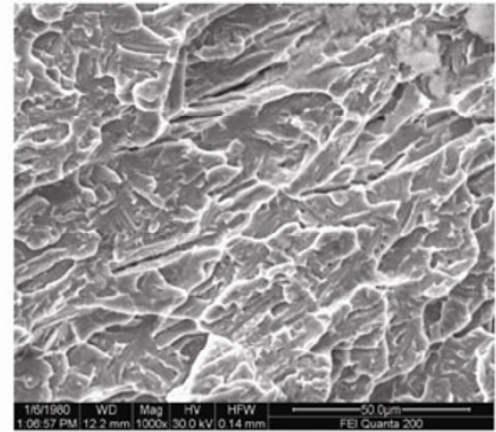

(b) Exp. No. 9

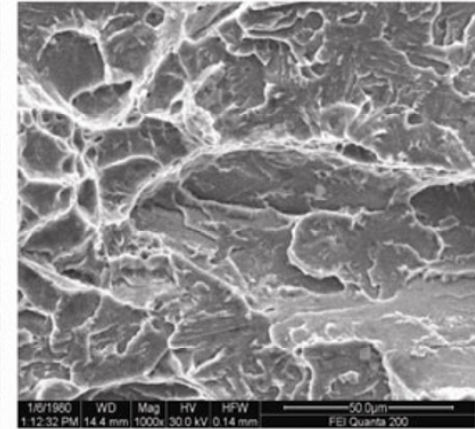

(c) Exp. No. 14

Fig. 12 Fractrographs of the Charpy V-notch tested samples at $-196{ }^{\circ} \mathrm{C}$.

The fracture toughness of a welded DSS by submerged arc weldments at subzero temperatures was investigated by Kacar and Acarer [26]. The flux-cored arc welds had higher tensile strength when compared to the parent metal, with a slightly decreased elongation. The strength of the materials increased and the ductility decreased with decreasing temperature, in a similar manner to that of 2205 duplex stainless steel [27]. At room temperature, the cleavage fracture occurred and consequently plastic deformation prevailed. The ductile behavior was verified. As tem- perature decreased, and at a certain low temperature cryo-temperature, the yield strength of ferrite became higher and its cleavage fracture occurred. At this stage, a transition from ductile fracture through plastic deformation to brittle fracture by cleavage occurred.

\section{Conclusions}

The following conclusions were drawn from this work.

1. The friction-welded DSS weldment had fine grain 
size in the PDZ, which resulted in higher hardness and strength of the joint.

2. The weld microstructure had nearly equal volume of austenite and ferrite phases.

3. The friction-welded DSS impact energy was much higher than the arc welding of DSS joints for both room-temperature and cryo-temperature conditions.

4. The impact fracture surface appeared as a transition from ductile fracture through plastic deformation to brittle fracture by cleavage.

5. The hardness value in the PDZ is much higher than the weld metal and base metal.

6. At cryo-temperatures, the toughness of the joints gets reduced to a greater extent.

Open Access: This article is distributed under the terms of the Creative Commons Attribution License which permits any use, distribution, and reproduction in any medium, provided the original author(s) and source are credited.

\section{References}

[1] Charles J. Composition and properties of duplex stainless steels. Welding in the World 36: 43-54 (1995)

[2] Vogt J B. Fatigue properties of high nitrogen steels. Mater Proc Tech 117: 364-369 (2001)

[3] Mateo A, Llanes L, Akdut N, Anglada M. High cycle fatigue behavior of a standard duplex stainless steel plate and bar. Mater Sci Eng A 319-321: 516-520 (2001)

[4] Hertzman S, Lehtinen B, Symniotis-Barradal E. Intermetallic phase formation and its effect on corrosion resistance of duplex stainless steel SS 2377 (UNS 31803). In Proceedings of Applications of Stainless Steel '92, Stockholm, Sweden, 1992: 345-359.

[5] Gunn R N. Reduction in fracture toughness due to intermetallic precipitates in duplex stainless steels. In Duplex America 2000 Conference on Duplex Stainless Steels, Houston, USA, 2000: 299-314.

[6] Nilsson J O. Super duplex stainless steels. Mater Sci Tech 8: 685-700 (1992)

[7] Thorvaldsson T, Eriksson H, Kutka J, Salwén A. Influence of microstructure on mechanical properties of a duplex stainless steel. In Proceedings of Stainless Steel '84, Göteborg, Sweden, 1984: 101-105.

[8] Karlsson L, Bengtsson L, Rolander U, Pak S. The kinetics of intermetallic phase formation in duplex stainless weld metals and their influence on mechanical properties. In Proceedings of Applications of Stainless Steel '92, Stockholm, Sweden, 1992: 335-344.

[9] Karlsson L. Duplex stainless steel weld metals-effects of secondary phases. In Proceedings of Duplex Stainless Steels '97, Maastricht, Netherlands, 1997: 43-58.

[10] Karlsson L, Rigdal S, Lake F. Effects of intermetallic phases in duplex stainless steel weldments. In Duplex America 2000 Conference on Duplex Stainless Steels, Houston, USA, 2000: 257-272.

[11] Liljas M. The welding metallurgy of duplex stainless steels. In Proceedings of Duplex Stainless steels '94, Glasgow, Scotland, 1994.

[12] Sato Y S, Nelson T W, Sterling C J, Steel R K. Pettersson C O. Microstructure and mechanical properties of friction stir welded SAF 2507 super duplex stainless steel. Mater Sci Eng A 397: 376-384 (2005)

[13] Cvijović ZM, Mihajlović D V, Knežević V R. Microstructural morphology and stability of rapidly solidified duplex stainless steel. Mat Sci Forum 282-283: 323-330 (1998)

[14] Li J, Zhang X, Liu L, Han L. Interfacial characteristics and dynamic process of $\mathrm{Au}$ - and $\mathrm{Cu}$-wire bonding and overhang bonding in microelectronics packaging. $J$ Microelectromech S 22(3): 560-568 (2013)

[15] Li J, Liu L, Deng L, Ma B, Wang F, Han L. Interfacial microstructures and thermodynamics of thermosonic $\mathrm{Cu}$-wire bonding. IEEE Electron Devic Lett 32(10): 1433-1435 (2011)

[16] Li J, Han L, Duan J, Zhong J. Interface mechanism of ultrasonic flip chip bonding. Appl Phys Lett 90(24): 242902 (2007)

[17] Li J, Duan J, Han L, Zhong J. Microstructural characteristics of $\mathrm{Au} / \mathrm{Al}$ bonded interfaces. Mater Charact 58: 103-107 (2007)

[18] Li J, Wang F, Han L, Zhong J. Theoretical and Experimental Analyses of Atom Diffusion Characteristics on Wire Bonding Interfaces. J Phys D: Appl Phys 41: 135303 (2008)

[19] Sahin M. Evaluation of the joint-interface properties of austenitic-stainless steels (AISI 304) joined by friction welding. J Mater Des 28: 2244-2250 (2007)

[20] Heino S, Knutson-wedel E M, Karlsson B. Precipitation behavior in heat affected zone of welded super austenitic stainless steel. J Mater Sci Technol 15(1): 101-108 (1999)

[21] Suutala N. Effect of solidification conditions on the solidification mode in austenitic stainless steels. Metall Mater Trans A 14: 191-197 (1983)

[22] Ibrahim O H, Ibrahim I S, Khalifa T A F. Impact behavior of different stainless steel weldments at low temperature. Eng Fail Anal 17: 1069-1076 (2010)

[23] Baek J-H, Kim Y-P, Kim W-S, Kho Y-T. Effect of temperature 
on the charpy impact and CTOD values of type 304 stainless steel pipeline for LNG transmission. J Mech Sci Technol 16(8): 1064-1071 (2002)

[24] Chan J W. Small punch testing for determining the cryogenic fracture properties of 304 and 316 austenitic stainless steels. Adv Cryogenic Eng 55: 38-45 (1992)

[25] Han G, Fukuyama S. Yokogawa K. Tensile behavior of

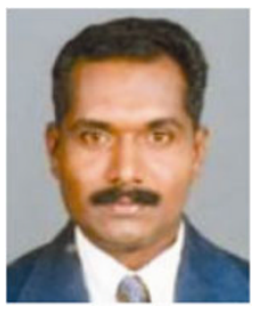

Puthuparambil Madhavan AJITH. $\mathrm{He}$ is a PhD candidate at Department of Production Engineering, National Institute of Technology, Tiruchirappalli, Tamil Nadu, India. He obtained his Bachelor degree in 1994 from Mahatma Gandhi University, Kottayam, Kerala, India and Master degree

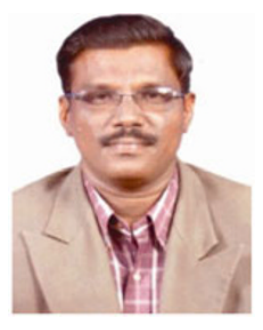

Paulraj SATHIYA. He received his bachelor degree in 1994 on Mechanical Engineering from Government college of Engineering, Salem, University of Madras, India, his Master degree in 1996 on Welding Engineering from Regional Engineering College, Bharathidasan University, India, and his $\mathrm{PhD}$ degree in 2006 from Bharathidasan University, India. He is currently working as an associate professor in Department of Production Engineering and associate dean (Planning \& Development) in National Institute of Technology, Trichy,

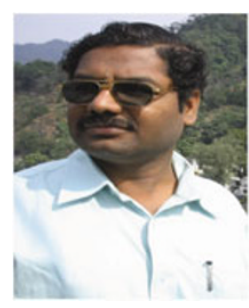

Sivanandam Aravindan. He received his Bachelor degree in Mechanical Engineering in 1990 from Bharathidasan University. He received Masters degree in Manufacturing Technology in 1993 from Annamalai University. He obtained $\mathrm{PhD}$ degree in 2000 from IITM, Chennai. After that, he did his post doctoral fellowship (JSPS) at Tokyo Institute of technology in Nano technology area. He is currently duplex stainless steel at low temperatures. Mater Sci Technol 15: 909-920 (1999)

[26] Kacar R, Acarer M. Microstructure-property relationship in welded duplex stainless steels. Mater Sci Eng A 363: 290-296 (2003)

[27] Sieurin H, Sandstom R. Fracture toughness of a welded duplex stainless steel. Eng Fract Mech 73: 377-390 (2006)

in 2009 from National Institute of Technology, Tiruchirappalli, Tamil Nadu, India. He is also currently working as associate professor, Department of Mechanical Engineering, Rajiv Gandhi Institute of Technology Government Engineering college, Kottayam, Kerala, India. His research areas include welding and optimization of parameters with different technique.

Tamilnadu, India. He is working in the area of welding technology, solid state joining, materials behaviour subjected to welding, similar and dissimilar materials welding, failure analysis of weldments, modeling and simulation of welding processes, and welding parameter optimization. He received Young Technology Award 2009, from Indian Welding Society, India and also received Young Scientist Award from Department of Science and Technology, New Delhi, India. He has published sixty papers in international and national reputed journals and fifty papers in international and national conferences.

working as a associate professor in Department of Mechanical Engineering, Indian Institute of Technology Delhi, Delhi, India. He is working in the area of welding, advanced materials processing and nano manufacturing. He received 2 best paper awards in national and international conferences. He filed two Indian patents. He successfully completed two funded projects. He published fifty five papers in international and national reputed journals and seventy papers in International and national conferences. 